\title{
A review of application of servqual model globally to measure perceived service quality in higher education
}

\author{
Linsha Thankachan
}

HR \& Administrative Executive, Vetphage Pharmaceuticals Pvt. Ltd.

*Corresponding Author: Linsha Thankachan

Email: linsha17@gmail.com

\begin{abstract}
Customer service and quality of the service provided are considered to be the most important and significant forces in a service driven organization. Customer satisfaction being the tool to measure if the expectations of the customers are met. The present research focuses on service quality provided by the higher education. Higher education in today's world is facing tremendous competition, thereby constantly looking forward to gain competitive advantage over other competitors. The customer set to be satisfied or more precisely the target customers being the students themselves, service quality provided depends mainly on the perceptions they hold about how well their needs and wants are being satisfied. These perceptions on quality service provided are made based on different factors and sets of services provided, be it the quality of teaching, infrastructure or other tangibles. The research here focuses on one such model which measures the service quality. The model discussed below is SERVQUAL Model given by Parasuraman et al. The research also focuses on how this model is being used effectively globally across different borders in order to bring improvements in the service provided, as change being the only constant while what varies is how and with what the needs are met and the expectations of the students as customers are met or exceeded for that matter.
\end{abstract}

Keywords: SERVQUAL, Service quality, Quality management, Higher education.

\section{Introduction}

\section{Higher education}

The international definition divided tertiary (post school) education into two parts. Type A being Higher Education and Type B being Further Education. A degree level higher education will take three years to be completed or more typically four. It mainly focuses on theoretical aspects along with focus on research activity. This allows the individual to be qualified to work in any of the professional field based on the education obtained by him or her. Thus, higher education mainly refers to university level education. The number of qualifications offered ranges from Higher National Diplomas and Foundation Degrees to Honors Degrees and as further step, Postgraduate programs such as Masters Degrees and Doctorates. The degrees mentioned are recognized throughout the world as it represents varied amount of skills and expertise required by the employers in their employees to be considered employable.

The post graduate studies where one can gain Master and Doctorate degrees are said to be included in Further education. They are the highest level of degree one can obtain. These degrees can be divided into two parts. A master's degree is awarded for a specialized course in a particular field after the bachelor's degree. Various categories being such as a Master of Arts, Master of Science, and Master of Theology. The amount of time one takes to earn a master's degree depends upon the program one is enrolled in, but minimum of two years is to be expected. The second type of graduate degree which is considered to be higher than a master's degree is a doctoral degree which is awarded for a particular course of study after the master's degree. Those who earn doctorates are given assume the title 'Doctor.' The amount of time one must study before earning such a degree varies greatly by field, institution Source: http://www.wg.aegee.org/ewg/higheredu.htm

\section{Servqual Model}

The SERVQUAL model was developed by A. Parasuraman and colleges in the USA. SERVQUAL model forms its basis from the expectations disconfirmation approach known as disconfirmation paradigm.

Service Quality $(\mathrm{S})=$ Perception $(\mathrm{P})-$ Expectation $(\mathrm{E})$

The model of service quality made by them significantly identifies the reasons for the gaps caused while delivering the service between customer expectations and perceptions. On studying the SERVQUAL model it can be seen that the model refers to different gaps. These gaps are divided into 5. Gap 5 is the product of gaps 1, 2, 3 and 4. If these four gaps, all of which are located below the line that separates the customer from the company, are closed the gap 5 will close. The gaps are as follows.

Gap 1 is the gap between what the customer expects and what the company's management thinks customers expect.

Gap 2 is the gap that occurs when management fails to keep up service standards that should meet customer expectations.

Gap 3 occurs when the company's service delivery systems - people, technology and processes - fail to deliver to the specified standard

Gap 4 occurs when the company fails to deliver as per the customer's expectations. It happens due to no proper communication between the employees and the consumer.

A 22 item SERVQUAL scale was developed in order to identify the extent of gap 5 . The core components on the basis of which the scale is prepared are divided into five namely the basic components of the service quality. The core dimensions are: reliability, assurance, tangibles, empathy and responsiveness.

Tangibles include external appearance consisting of infrastructural facilities, equipment used etc. 


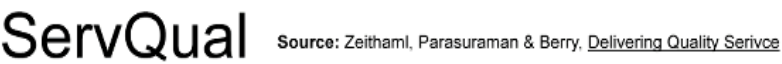

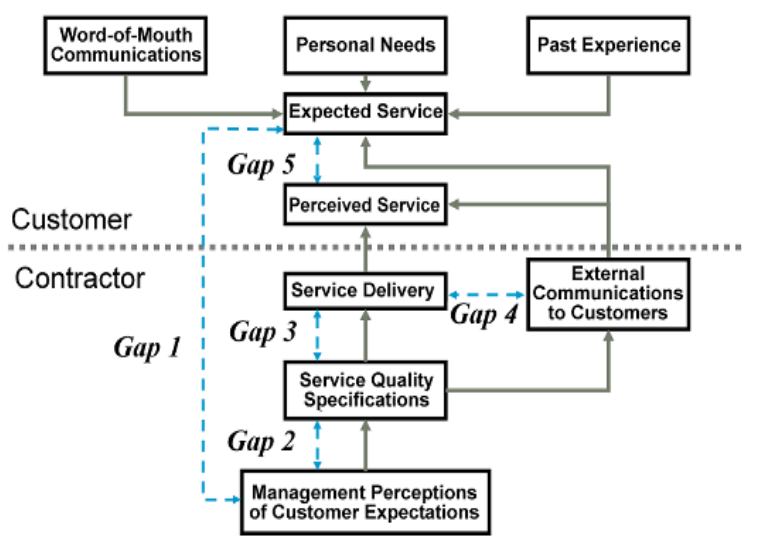

Reliability is ability of the organization to fulfill the given promises accurately

Responsiveness indicates the willingness of the organization in providing services to the customers as well as showing flexibility by adapting to the changing preferences of the customers

Assurance means the amount of trustworthiness gained by the organization by their customers (This category includes these measured components: competence, courtesy, credibility and security)

Empathy signifies personal attention given to the customer preferences and their needs. (Includes access, communication and understanding the customer)

Source: www.marketingstudyguide.com

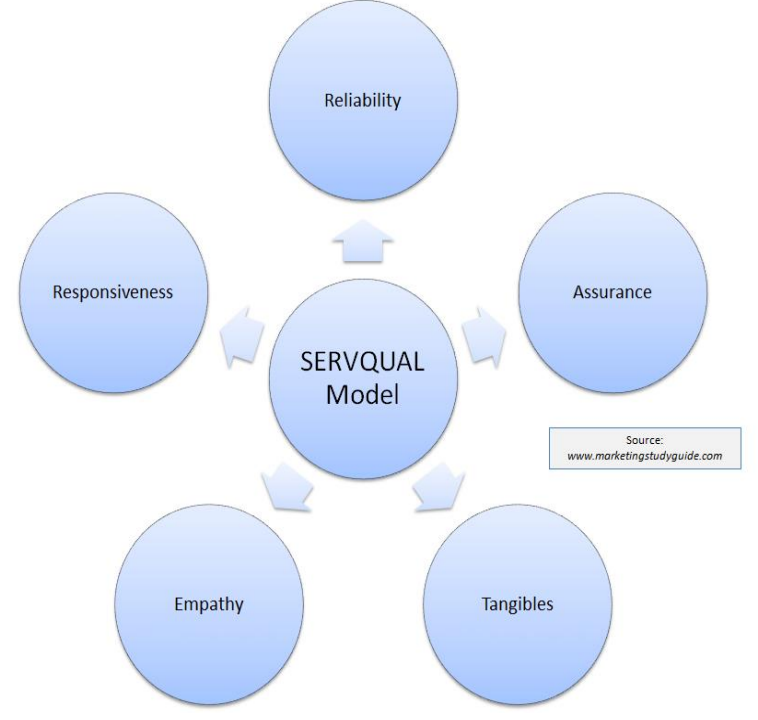

As the significance of each variable is measured it enables us to measure also the importance of gaps between expectation and perceptions. Management can then focus on strategies and tactics to close the important gaps. Thus, SERVQUAL model can be used to identify where the organization stands in the eyes of customers and where the necessary improvements have to be made in order to gain a competitive advantage.

\section{Literature Review Application of SERVQUAL model}

Naik and Gantasala ${ }^{1}$ conducted a study on SERVQUAL and its effect on customer satisfaction in retailing. It was concluded that communication needed to be improved between the staff members so that error free transactions are carried out. Training of staff was necessary in matters regarding communication skills, basic etiquettes etc. Thus the entire SERVQUAL model was used to identify the gaps between the expectations and perceptions and the reasons for the gap as well. Ravichandran ${ }^{2}$ conducted a study on Influence of Service Quality on Customer Satisfaction Application of Servqual Model in private banks and came up to a conclusion that the overall satisfaction of the customers needed to be increased, thus this study focused on the five core components of the model like tangibility, responsiveness etc. and used the same to identify which component needed improvement as whole or in parts for that matter. Butt and Run $^{3}$ in their study on Private healthcare quality in Malaysia: applying a SERVQUAL model concluded that healthcare being a sector where customer satisfaction and perception plays a key role, SERVQUAL model plays a role of a robust instrument which if applied with accuracy can determine the faults and gaps in the service provided based on the expectations and perceptions. This instrument was majorly used by the Malaysian Healthcare Providers.

Kumar and $\mathrm{Kee}^{4}$ in their study on Comparative evaluation of critical factors in delivering service quality of banks: An application of dominance analysis in modified SERVQUAL model. The study was conducted in private banks located in different parts of Malaysia. The conclusion which was drawn said that the significance of components of the model varied from bank to bank. The service quality gap identified differed in reference to the components like tangibility, reliability, competence, convenience and responsiveness between different banks within same region. Akbaba $^{5}$ conducted a study on measuring service quality in the hotel industry: A study in a business hotel in Turkey. The conclusion that he came up to was that the instrument SERVQUAL model used by the industry proved to be successful in identifying the customer expectations on the basis of all the four components. Apart from the five core dimensions, there were many such areas which were also explored and corrected.

Jieng and $\mathrm{Klien}^{6}$ also in their study On Measuring Information System Service Quality: Servqual from the Other Side confirmed the importance of measuring existing service quality and using SERVQUAL model as a powerful tool for the same. Shahin ${ }^{7}$ conducted a study on SERVQUAL and Model of Service Quality Gaps: A Framework for Determining and Prioritizing Critical Factors in Delivering Quality Services. The study was conducted in Iran which concluded that SERVQUAL model being a powerful tool to measure the difference between customer expectation and perception, could be used effectively to identify internal 
service quality along with external service quality. Kouthouris and Alexandris ${ }^{8}$ conducted a study on Can service quality predict customer satisfaction and behavioral intentions in the sport tourism industry? An application of the SERVQUAL model in an outdoors setting. The above mentioned study was conducted in Greece. The conclusion drawn was that universal applicability of the model is doubtful as one of the segments of the industry could not be valued. Even Satisfaction levels and behavioral intentions could not be measured.

Babakus and Mangold ${ }^{9}$ conducted a study on Adapting the SERVQUAL Scale to Hospital Services: An Empirical Investigation. The study was conducted for determining the service quality of healthcare services. It was concluded that effectiveness of the SERVQUAL model used in hospital and healthcare is sufficient find the gaps and enhance the service quality in various dimensions. Saleh and Ryan ${ }^{10}$ conducted a study in Canada on Application of SEVQUAL model in hospitality industry again reconfirming the efficiency of the model to determine and measure service quality gaps along with measuring the service quality at various dimensions.

\section{Application of SERVQUAL Model: Higher education}

Yousapronpaiboon \& Johnson ${ }^{11}$ conducted a study on SERVQUAL: Measuring higher education service quality in Thailand. They came up to a conclusion that all the five core components scored different in terms of expectations and perceptions. While at some point component like tangibility was weaker and at some points components like reliability were less. The main purpose of the study was to measure the student satisfaction in terms of the education provided to them. It also identified service quality gaps in terms of communication between staffs and also between staff and students.

Aklaghi and Amini ${ }^{12}$ conducted a study on evaluating educational service quality in technical and vocational colleges using SERVQUAL model. The study was conducted in Iran. It showed that in the present education system Service quality gaps were found in all dimensions. Most being in the responsiveness and least being in reliability.

Abaria, Yarmohammadian \& Esteki ${ }^{13}$ conducted s a study on Assessment of quality of education a nongovernmental university via SERVQUAL model. The study was conducted in Azad University Khorasgan. The study showed that all the dimensions of the model had a significant effect on the satisfaction while other variables which affected were empathy, confidence, and assurance.

Gallifa $(2010)^{14}$ conducted a study on Student perceptions of service quality in a multi-campus higher education system in Spain. They concluded that in a multi campus system, each and every campus had a varying degree of quality profile based on student perceptions. Campus related perception of students proved to be a gateway for future improvements. Among different year students, the final year students shared the most critical and clear perception and evaluation which helped the campuses to get an accurate idea about the deficiencies in the campus
Kandampully and Hussain (2009) ${ }^{15}$ conducted a study on Students' perceptions of service quality in higher education. The study was conducted in Ohio. It was concluded that Reliability and dimensionabiltiy played a key role. But if education sector is taken into consideration then the model would measure on the basis of two core components which are tangibility and intangibility.

Oliveira \& \& Ferreira ${ }^{16}$ conducted a study on Adaptation and application of the SERVQUAL scale in higher education. The study was conducted in higher education institutes in parts of Brazil. The study concluded that education and especially higher education plays a key role in economic, social and technological development of a country. Thus measuring the service quality provided in the education sector plays a significant role, thereby causing necessary improvements. And SERVQUAL model proves to be an effective tool.

Hasan, Ilias, Rahman, \& Razak ${ }^{17}$ conducted a study on Service Quality and Student Satisfaction: A Case Study at Private Higher Education Institutions in Malaysia. The conclusions were that student satisfaction and service quality are positively related. The two most important dimensions for enhancing student satisfaction were proved to be empathy and assurance.

Zafiropoulos and Vrana (2007) ${ }^{18}$ conducted a study on Service Quality Assessment In A Greek Higher Education Institute. They concluded that there is difference in the overall view of students and staffs. Staff in spite of higher expectation always kept high perception while students had lower expectation and perceived lower for the institutes as well. Thus it showed how the experience gained by staff in other institutes make them expect more from the institutes they are moving into while students being new to the exposure didn't hold much expectations nor perceived more. As the students moved from first year to the final year the expectations kept on decreasing while the perceptions kept on becoming clear. Thus the negative score of service quality kept decreasing.

Arambewala and Hall $(2006)^{19}$ conducted a study to measure international student satisfaction using SERVQUAL model. The conclusion that he came up to was that the satisfaction levels and the factors associated with it varies from country to country. Where Indians gave significant importance to competitive fees, students from China gave it the least importance. Thus different components had different impact on student satisfaction. While the dimension which affected the most was identified to be tangibility.

Chua $(2004)^{20}$ conducted a study on perception of quality in higher education in Canada. The study concluded that different stakeholders of education system saw quality in different aspects. Or parents what mattered the most was input and output while for students' process mattered the most. The management focused on input, process and output while the employers gave importance to output more. Thus all the aspects from different views make a quality education. 


\section{Conclusion}

SERVQUAL Model was first developed by Parasuraman and a team of American scientists in 1988. This model became an effective tool put to use for measuring the service quality of the organizations. It focuses on five core components to determine the service quality which are tangibility, responsiveness, reliability, empathy and assurance. It also focuses on service gaps caused due to deficiency in various factors like communication thus causing varied amounts of expectations and perceptions. Thus it includes and holds responsible every stakeholder of the organization for provision of better service quality. May it be the customer, employer or employees.

According to the various research papers reviewed, it was observed that the model had been put to use in various service sectors in order to measure the service quality. It was proved to be an effective tool in identifying the significance of all the five dimensions. The sectors most commonly used in, being banking, hospitality and hospital and health care. The use of SERVQUAL model in higher education was initiated in early 2000s, where the popularity of the model had increased. Various researches have been conducted to measure the quality of higher education. Thereby measuring the student satisfaction and student perceptions, along with their parents as valuable customers.

The significant observation made out of all the researches conducted, one such observation was the use of SERVQUAL model globally. Most of the researches were conducted across the national borders of India. The model was exploitatively put to use in places like Malaysia, Canada, Iran, Singapore etc. This shows how valuable they consider the feedback of their customers and how effectively they put SERVQUAl model to use.

Many Indian scientists have used this model to measure the service quality and then make necessary improvements and fill the service gaps as identified through the model. But as mentioned earlier the use of this model is limited in India.

The world is getting highly competitive with organizations striving for change that would attract the customers. The preferences of the customers are changing at a faster pace. Thus at this pace it becomes a need for the organizations to constantly update and improvise on what they have and fill in the gaps of what they don't have. Assessing the service quality steps in here.

SERVQUAL model can be used in variety of service settings. Comparison of competitors and varied range of services are possible through this model. Internal marketing can be best done using this model. It works on the principle that every individual in an organization is responsible for satisfying the customers and improving the service quality. Internal service quality and external service quality go hand in hand. So are customer loyalty, customer satisfaction and profitability and wealth maximization of the organization. SERVQUAL model is an important part of market research and knowing the customers. Thus, in whole SERVQUAL model covers all the aspect of an effective management be it Marketing, Human Resource Management or Finance. To survive in this fast paced world, SERVQUAL model proves to be an effective instrument for the assessment of the service quality. And it should be put to use in India as much as it is being, globally.

\section{Source of funding}

None.

\section{Conflict of interest}

None.

\section{References}

1. Naik C. N. K, Gantasala. S. B., Prabhakar G.V. Service Quality and its effect in retailing. Eur J Soc Sci 2010;16(2) 232-43.

2. Ravichandran, K., Mani, B.T., Kumar, S.A, Prabhakaran. Influence of Service Quality in Customer Satisfaction: Application of SERVQUAL model. Int J Business Manag 2010;5(4).

3. Butt M. M. \& Run E. C. Private Health Care QualityApplication of SERVQUAL Model. Int J Health Care Qual Assurance 2009;23(7).

4. Kumar, M., Kee, F. T. \& Charles, V. Comparative Analysis of critical factors in delivering service quality of banks. Int J Qual Reliability Manag 2009;27(3):358-78.

5. Atilla A. (August, 2006). Measuring Service Quality in Hotel Industry. Int J Hospitality Manag 2006;170-92.

6. Jiang J. J., Klein G. and Carr C. L. Measuring Information System service quality: SERVQUAL from other side. MIS Quarterly. 2006;26(2):145-66.

7. Shahin A. SERVQUAL and Model of Service Quality Gaps 2009.

8. Kouthouri C. \& Alexandris, K. An application of SERVQUAL model in outdoor activity. Journal of Sport Tourism 2005;10(2):101-11.

9. Babakus E. \& Mangold W. G. Adapting SERVQUAL scale to hospital services. HSR Health Services Research. 1992;26:6

10. Saleh F. \& Ryan C. Analysing Service Quality in the Hospitality Industry Using the SERVQUAL Model. The Service Industries J 2006;11(3).

11. Yousapronpaiboon K. and C. Johnson W. Measuring hospital out-patient service quality in Thailand. Leadership Health Ser, 2013;26(4):338-55.

12. Akhlaghi E., Amini S., \& Akhlaghi H. Evaluating Educational Service Quality in Technical and Vocational Colleges using SERVQUAL Model. Procedia - Soc Behav Sci, 2012;46:5285-9.

13. Abaria A.A., Yarmohammadian M.H. \& Estekic M. (2011). Assessment of quality of education a non-governmental university via SERVQUAL model. Procedia Social and Behavioral Sciences 2011;15:2299-2304.

14. Gallifa J. \& Batalle P. Student Perceptions of Service Quality in a Multi-Campus Higher Education System in Spain. Quality Assurance Educ 2010;18(2):156-70.

15. Nadiri H., Kandampully J. \& Hussain K. Student Perception of Service Quality in Higher Education. Total Qual Manag Business Excellence 2009;20(5):523-35

16. Oliveiro, O. J. \& Ferreira, E. C. (May, 2009). Adaptation and application of SERVQUAL scale in Higher Education.

17. Hasan, H.F.A, Ilias, A., Rahman, R.A. \& Razak, M.Z.A. (2008), Service Quality and Student Satisfaction. Int Business Res 2008;1(3):163-75.

18. Zafiropoulos C, \& Vrana V. Service Quality Assessment in Greek Higher Education Institutes. J Business Econ Manag 2008;9(1):33-45 
19. Arambewela R, and Hall J. Comparative analysis of International Education Satisfaction using SERVQUAL model. J Serv Res 2006;145-166.

20. Chua, C. (2007). Perception of Quality in Higher Education. Proceedings of the Australian Universities Quality Forum 2004.

How to cite this article: Thankachan L. A review of application of servqual model globally to measure perceived service quality in higher education. J Manag Res Anal 2019;6(3):142-6. 